\title{
Distance Teaching and Learning of Science during the COVID-19 Pandemic in Greece: Views of K-6 Students
}

\author{
Achilleas Mandrikas (Corresponding author) \\ Department of Primary Education, National and Kapodistrian University of Athens, GR \\ 13 Navarinou str., Athens 106 80, Greece \\ Tel: 30-210-995-5717_E-mail: amandrikas@gmail.com
}

Ioanna Stavrou

Department of Primary Education, National and Kapodistrian University of Athens, GR

13 Navarinou str., Athens 106 80, Greece

Tel: 30-210-645-1005 E-mail: istavrou@primedu.uoa.gr

$$
\text { Kyriakos Kyriakou }
$$

Department of Primary Education, National and Kapodistrian University of Athens, GR

13 Navarinou str., Athens 106 80, Greece

Tel: 30-210-412-1791 E-mail:kyriakkyr@yahoo.gr

Constantina Stefanidou

Department of Primary Education, National and Kapodistrian University of Athens, GR

13 Navarinou str., Athens 106 80, Greece

Tel: 30-210-760-9245 E-mail: sconstant@primedu.uoa.gr

Constantine Skordoulis

Department of Primary Education, National and Kapodistrian University of Athens, GR

13 Navarinou str., Athens 106 80, Greece

Tel: 30-210-368-8008Ｅ-mail: kskordul@primedu.uoa.gr 


\title{
Ml Macrothink
}

Received: Nov. 7, 2021

Accepted: Dec. 24, 2021

Published: February 1, 2022

doi:10.5296/jse.v12i1.19463

URL: https://doi.org/10.5296/jse.v12i1.19463

\begin{abstract}
In this paper the findings from research conducted with primary education students (K-6) are presented, explicitly focusing on students' views concerning how Science was taught through distance learning due to the COVID-19 pandemic during the school year 2020-21. The sample of 378 students was not satisfied by the distance teaching and learning of Science except for the increased use of supporting audiovisual resources. Some of the results that occurred due to this transition were technical connection problems, a lack of communication between classmates and their teacher, a lack of concentration by students, their limited personal participation and the absence of face-to-face experimentation. Consequently, the limited understanding of scientific concepts shaped the students' preference for learning Science in real classroom conditions.
\end{abstract}

Keywords: distance teaching and learning, science education, primary education, pandemic 


\section{Macrothink}

\section{Introduction}

The COVID-19 pandemic affected education worldwide. According to data from the European Union (Di Pietro et al., 2020) as well as data from UNESCO (UNESCO, 2021, p.7) 186 countries took suspending measures of face-to-face education at all levels of education affecting 1.5 billion learners. Greece is one of the countries with the longest period of suspension of schools at all levels (for primary education 11/3-31/5/2020, 18/11-23/12/2020, $11 / 2-23 / 4 / 2021)$.

The suspension of the educational process due to the COVID-19 pandemic was accompanied by compulsory distance learning, initially asynchronous, and then in synchronous form (online learning). Despite the fact that through distance learning an effort was made to ensure the continuity of the learning process, a number of problems emerged mainly of which related to the quality of the learning process. In general, the problems arising from the implementation of distance teaching and learning are related to the technological equipment available to students (Di Pietro et al., 2020; UNESCO, 2021), to the conditions prevailing in their home environment, to the difficulties that students face in terms of self-discipline, motivation and course preferences (Ferraro et al., 2020; Radha et al., 2020) and to the internal difficulties of laboratory courses such as those of Science (Center for Studies and Documentation/KEMETE, 2021).

This paper explores the views of 6th grade (K-6) students on distance teaching and learning in Science (in Greece Physics, Chemistry, Biology are taught as an integrated subject in the last two grades of primary education). We chose to address only the students of the 6th grade, because they are the oldest grade in primary education and therefore more able to formulate evaluative judgments compared to younger students. But, also because they have more experience in learning Science compared to those of 5th graders. A key criterion for the selection of the research topic was that distance teaching and learning in Science implemented in wider audiences without having been investigated how it is perceived by primary education students.

\section{Literature review}

The term "distance education" refers to a number of synchronous and asynchronous types of education based on the use of technological means, which cover the lack of physical presence of students and teachers (Gewin, 2020). "Online learning" refers to the type of synchronous education where teachers and students interact in real time, regardless of whether they are in different locations. In this model, students are usually invited to participate in learning activities at a specific time through a digital platform. "Online learning" is considered a kind of "live teaching", where the participation of students in the learning process aims to create a more structured class, while at the same time the interaction between class members is enriched (Watts, 2016).

According to many researchers an important component of "online learning" is the active involvement of students and the interaction between participants during the distance teaching and learning process (Muzammil et al., 2020; Thurmond \& Wambach, 2004). This interaction 
promotes the process of student involvement and is an important factor in terms of learning outcomes (Gray \& Diloreto, 2016; Martin \& Bolliger, 2018). The active involvement of students in distance teaching and learning relates to the relationships that exist between students, to the relationships that exist between students and teachers, to the motivation of each student as well as the results of each lesson (Angelova, 2021; Gray \& Dilorero, 2016; Muzammil et al. 2020; Watts, 2016). Therefore, some researchers suggest effective ways to keep students constantly involved in the learning process in a distance learning environment (Meyer, 2019).

In a report by OECD the education responses of 98 countries all over the world to the COVID-19 pandemic are examined. In this report, some fundamental educational parameters were recorded: educational priorities in response to the crisis, the availability of technological infrastructure in school or at home, access to the internet, readiness of students to learn online, readiness of teachers to teach online, sufficient availability of adequate software etc (Reimers \& Schleicher, 2020).

In a similar report the European Union concludes that "students will suffer a learning loss" during the COVID-19 pandemic (Di Pietro et al., 2020, p. 2) as well as short-term and long-term consequences of "remote schooling" are reported. Some of them were clearly acknowledged by educational institutions, like less time spent learning, symptoms of stress in students increased, changes occurred in the ways students interact, and a severe lack of motivation. The most important finding of this report was the emergence of inequalities among students in every country. "The switch from offline to online learning caused by COVID-19 is likely to negatively affect those children, in primary and lower secondary schools, who have higher difficulties in adapting to the new learning environment. The switch is also expected to exacerbate existing educational inequalities." (Di Pietro et al., 2020, p. 4).

Inequality in learning opportunities during COVID-19 pandemic was referred in several researches (Jæger \& Blaabæk, 2020; Moroni et al., 2020; Pensiero et al., 2020; UNESCO, 2021). Although most research has been done in higher education (Angelova, 2020; Gewin, 2020; Martin, \& Bolliger, 2018; Radha et al., 2020; Sharin, 2021; UNESCO, 2020), learners' limited engagement, psychological impacts and technological difficulties have been recorded as frequent consequences of online learning. Particularly, internet accessibility and a lack of communication with classmates and teachers were identified as high challenges of online education (Bisht \& Jasola, 2020). Students experienced a decline in wellbeing, motivation, and had trouble concentrating on their studies during online education (Azlan et al., 2020), which was sometimes due to home distractions (Besser et al., 2020). Students were disengaged and participation was not immediate as in class, as summarized in previous of COVID-19 pandemic research (Chen et. al. 2010; Thurmond \& Wambach, 2004). Even if students were positive for online learning, they preferred real class conditions at a rate of 77,71\% (Radha et al., 2020, p. 1093).

Another research confirmed these findings from teachers' perspective. An et al. (2021) concluded that the major challenges faced by teachers during COVID-19 pandemic included a lack of student participation and engagement, students without access to technology, and no 


\section{Macrothink}

face-to-face interactions with students. Summarizing the findings of several research about online courses, Jaggars and $\mathrm{Xu}$ (2016) found that quality courses were characterized by clearly written objectives, well-organized content, a variety of opportunities for interpersonal interaction, and effective use of technology (Jaggars \& Xu, 2016).

In Greece, research about education response during the COVID-19 pandemic has just started publishing. Karadimou \& Tsioumis (2021) investigated the general impact of the COVID-19 pandemic on the Greek educational community focusing on official instructions derived from Ministry of Education based on a conceptual knowledge rather than an empirical knowledge. Geropoulos et al. (2021) recorded 43 secondary head teachers' views about difficulties of distance learning during the first period of the COVID-19 pandemic (March-May 2020) revealing lack of technological equipment, distribution of computers in large families, support of different family background, educational inequalities of vulnerable groups, and internet access at school. Gkaintartzi (2021) recorded 27 primary and preschool teachers' views about challenges on refugee students' education during the first period of the COVID-19 pandemic (March-May 2020). So far, there is lack of research on students' views about distance education implemented during the COVID-19 pandemic.

Moreover, although there is rich literature on the importance of distance education and the factors that affect it, there is limited research related to primary students' views on distance teaching and learning, particularly in Science and during the COVID-19 pandemic. This is the reason we decided to examine how K-6 students in Greece experienced the situation of distance teaching and learning of Science during the COVID-19 pandemic.

\section{Method}

\subsection{Research question}

The main research question is: What are K-6 students' views on the distance teaching and learning of Science that was implemented due to the COVID-19 pandemic during the school year 2020-21? This question is intended to be answered by considering students' views on four parameters:

a) the content and the topics of the subject

b) the quality of internet connection

c) the communication between the student with the teacher and his/her classmates

d) the personal approach and involvement of each student in the distance teaching and learning process.

\subsection{Sample}

The sample for the research consisted of 378 K- 6 students, who came from 24 public primary schools of the Prefecture of Attica, to which the research team had access. These students had been taught the subject of Science in primary education for two school years, of which 6 months were taught online. Specifically, they were taught online between March 11th to May 31 st of 2020, between November 18th to December the 23rd of 2020, as well as between 


\section{Macrothink}

February 11th to April 23rd of 2021.

\subsection{Data collection}

A questionnaire containing 21 Likert scale (1-5 or 1-3) closed-ended questions and 2 open-ended questions was used as a research tool. The questions were structured in four categories, according to the four parameters mentioned above. These categories were formed by the research team based on respective classifications in similar research (An et al., 2021; Di Pietro et al., 2020; Gray \& Dilorero, 2016; Muzammil et al. 2020; Reimers \& Schleicher, 2020).

Regarding the validity of the questionnaire, that is to what extent this questionnaire measures what it is made to measure, it is provided by the fact that all questions are related to students' views on distance teaching and learning of Science (content validity). Also, the questionnaire includes all aspects of distance teaching and learning of Science, as they are classified in four categories:

a) the content and the topics of the subject (6 out of 23 questions).

b) the quality of internet connection (4 out of 23 questions).

c) teacher-student and student-student communication (7 out of 23 questions).

d) personal approach and involvement of each student (6 out of 23 questions).

Moreover, the questionnaire is tested by two experienced primary teachers in order to adjust the language at the primary students' level. Finally, it was followed by clear instructions, written for primary students to explain to them how to complete the questionnaire.

The questionnaire was created in digital format and sent via internet accompanied by a letter to students and their parents. The researchers addressed primary education teachers, who in turn informed the students of the link containing the questionnaire and students answered the questionnaire at home after class hours.

\subsection{Data analysis}

The answers to the closed-ended questions were classified based on prepared answers and were recorded in tables with a percentage distribution. Regarding the open-ended answers, a qualitative content analysis method was used to analyze the data (Mayring, 2015). The texts for analysis were given to a second coder along with the analytical rules, such as units, coding agenda, category definition and level of abstraction for inductive formation. The points of disagreement with the second coder were recorded by a third coder. Quantitative steps of analysis, i.e. percentages, the so-called descriptive statistics, helped quantify the findings and provide a clear picture of participants' views on distance teaching and learning of Science.

The trustworthiness of this research was checked by implementing compatible quality criteria. Peer debriefing was used to increase the credibility of the data analysis, while coding agreement was another strategy used to enhance trustworthiness. However, there is still a risk 
that some questions were not fully understood by the 6th grade students and this remains one of the limitations of the research.

\section{Results and Discussion}

\subsection{Regarding the content and the topics of the subject}

Six questionnaire questions were intended to record the students' genuine interest in Science. As shown in Table 1 , the vast majority of the sample $(83,6 \%)$ generally had a high level of interest in Science.

Table 1. My interest in Science

\begin{tabular}{|c|c|c|c|c|}
\hline very high & high & moderate & poor & none \\
\hline $35,7 \%$ & $47,9 \%$ & $13,8 \%$ & $2,4 \%$ & $0,3 \%$ \\
\hline
\end{tabular}

Table 2 clearly shows that the way Science was taught in the classroom was considered very satisfactory by most students. The largest percentage of students $(53,2 \%)$ answered "very much" and 37,3\% answered "much" indicating that over $90 \%$ of students had positive evaluations of the way the subject was taught in the classroom.

Table 2. How did you enjoy Science as it was taught in the classroom?

\begin{tabular}{|c|c|c|c|c|}
\hline very much & much & moderately & a little & not at all \\
\hline $53,2 \%$ & $37,3 \%$ & $7,1 \%$ & $2,1 \%$ & $0,3 \%$ \\
\hline
\end{tabular}

However, Table 3 clearly shows that this satisfaction was mitigated when the Science course was taught through distance learning. The largest percentage of students $(39,7 \%)$ stated a "moderate" preference, the positive preferences from the previous question decreased and the negative preferences increased considerably. This clear preference of having Science taught face-to-face is expected to be justified with specific arguments or choices in subsequent questions of the questionnaire and to be stated as the final preference in the last question.

Table 3. How much did you enjoy Science as it was taught by distance?

\begin{tabular}{|c|c|c|c|c|}
\hline very much & much & moderately & a little & not at all \\
\hline $7,7 \%$ & $25,1 \%$ & $39,7 \%$ & $18,8 \%$ & $8,7 \%$ \\
\hline
\end{tabular}

Table 4 shows the percentages of students who stated that they were taught by distance specific topics of the Science textbook in the 6th grade. The content of the topics of the Science textbook is defined by the Greek National Curriculum. However, the order of teaching the topics is decided by each teacher depending on his/her previous experience and the level of readiness of his/her students. For this reason, each class - even in the same school 
- may have been taught different topics by distance, although the suspension of live teaching was common for all primary schools in Greece.

Based on students' answers we can observe that important topics of Physics, such as electromagnetism, light, heat, mechanics, and energy were taught extensively by distance, as teachers could find rich supervisory material for their teaching, such as simulations and videotaped experiments. On the contrary, the Chemistry topic "acids, bases, salts" was preferred to be taught in real class conditions, as the involvement of students in the experiments may have been considered necessary. Similarly, important topics of Biology, such as the circulatory system, living and non-living beings and the respiratory system, were taught mainly by distance, while more sensitive topics, such as infectious diseases and the human reproductive system, were taught in real class conditions by the choice of teachers.

Table 4. Topics of the Science textbook taught by distance in the 6th grade

\begin{tabular}{|l|c|l|c|}
\hline \multicolumn{1}{|c|}{ Topic } & $\begin{array}{c}\text { Percentage of } \\
\text { students } \\
\text { taught online }\end{array}$ & \multicolumn{1}{|c|}{ Topic } & $\begin{array}{c}\text { Percentage of } \\
\text { students } \\
\text { taught online }\end{array}$ \\
\hline Electromagnetism & $54,5 \%$ & Mechanics & $35,7 \%$ \\
\hline Light/Optics & $46,8 \%$ & Energy & $35,4 \%$ \\
\hline Heat/Thermal phenomena & $42,1 \%$ & Infectious diseases & $24,3 \%$ \\
\hline Human circulatory system & $37,3 \%$ & $\begin{array}{l}\text { Plants, Animals, } \\
\text { Ecosystems }\end{array}$ & $23,5 \%$ \\
\hline Living and non-living beings & $36,5 \%$ & Acids, Bases, Salts & $17,5 \%$ \\
\hline Human respiratory system & & \multicolumn{1}{|c|}{ Hum } & $18,3 \%$ \\
\hline
\end{tabular}

Table 5 shows the activities that increased during the distance teaching and learning of Science according to the students of the sample. It is obvious that the use of digital applications, such as watching videotaped experiments $(62,2 \%)$, the display of general informative videos $(35,2 \%)$ and the use of simulations $(26,5 \%)$ has increased. At the same time, however, more teacher-centered practices increased, such as the teacher's speech $(59 \%)$, the completion of the exercises in the textbook $(38,4 \%)$ and the description of the pictures in the textbook $(32,8 \%)$. In contrast, more student-centered practices, such as students' drawing $(19,7 \%)$ and student discussions $(18,5 \%)$, were reported by significantly lower percentages of students. The above chosen answers were formulated in the questionnaire by the researchers. In the open choice "other", only 7,14\% of the students answered, of which about 2/3 reported that during distance teaching and learning of Science "quizzes" increased. 
Table 5. Activities increased during the distance teaching and learning of Sicience

\begin{tabular}{|l|c|}
\hline Activity & $\begin{array}{c}\text { Percentage of students who } \\
\text { mentioned }\end{array}$ \\
\hline Watching videotaped experiments & $62,2 \%$ \\
\hline Teacher's speech & $59 \%$ \\
\hline Completion of the exercises in the textbook & $38,4 \%$ \\
\hline Display of general informative videos & $35,2 \%$ \\
\hline Description of the pictures in the textbook & $32,8 \%$ \\
\hline Watching simulations & $26,5 \%$ \\
\hline Creation of drawings by students & $19,7 \%$ \\
\hline Discussion between students & $18,5 \%$ \\
\hline Other & $7,14 \%$ \\
\hline
\end{tabular}

Table 6 confirms that the teacher-centered form of Science teaching prevailed during distance teaching and learning, as students' active and practical activities were decreased greatly. An important part of the sample $(68,5 \%)$ found that discussion between the students decreased and a significant $38,1 \%$ found that the creation of drawings by students also decreased. On the contrary, the percentages of students who found that standard teacher-centered activities were decreased ranged from 10-20\% (teacher's speech, completion of the exercises in the textbook, description of the pictures in the textbook). Concerning the displays by technological means and equipment, it seems that they decreased in $12-16 \%$ of the cases (Table 6) but increased in $26-62 \%$ of the cases (Table 5).

In the open choice of "other" decreased, answered by $15,6 \%$ of the students, doubled in comparison with those who answered the corresponding previous question. Among these students, about $6 / 10$ reported that experiments and their own participation conducting them decreased and 1/10 reported that group work decreased. It is noticeable that K-6 students mentioned in an open-ended question these characteristics of the teaching of Science, as they are included in the aims of the subject. 
Table 6. Activities decreased during the distance teaching and learning of Science

\begin{tabular}{|l|c|}
\hline Activity & $\begin{array}{c}\text { Percentage of students who } \\
\text { mentioned }\end{array}$ \\
\hline Discussion between students & $68,5 \%$ \\
\hline Creation of drawings by students & $38,1 \%$ \\
\hline Description of the pictures in the textbook & $19,6 \%$ \\
\hline Completion of the exercises in the textbook & $15,9 \%$ \\
\hline Watching simulations & $15,9 \%$ \\
\hline Watching videotaped experiments & $14,6 \%$ \\
\hline Display of general informative videos & $12,7 \%$ \\
\hline Teacher's speech & $10,6 \%$ \\
\hline Other & $15,6 \%$ \\
\hline
\end{tabular}

\subsection{Regarding the quality of the internet connection}

Four questionnaire questions were intended to record the quality of the students' internet connection, which affects the conduct and effectiveness of distance learning in all subjects including Science. As shown in Table 7, half of the students $(52,9 \%)$ used laptops and the other half shared between a desktop computer, a mobile phone and other means. As "other means" the combination of the three options as well as their connection to a TV set were referred to.

Table 7. Students' technology used during distance teaching and learning of Science

\begin{tabular}{|c|c|c|c|c|}
\hline desktop & laptop & mobile phone & other & no participation \\
\hline $17,5 \%$ & $52,9 \%$ & $12,7 \%$ & $16,7 \%$ & $0,3 \%$ \\
\hline
\end{tabular}

Table 8 shows the characterization given by the students to the quality of their internet connection during the distance teaching and learning of Science. More than $1 / 3$ described it as moderate, another $1 / 3$ described it as good and $1 / 5$ had a very good connection. On the contrary, poor quality of internet connection was found to be very low. 
Table 8. Students' internet connection during the distance teaching and learning of Science

\begin{tabular}{|c|c|c|c|c|}
\hline very good & good & moderate & poor & very poor \\
\hline $21,2 \%$ & $35,7 \%$ & $36,2 \%$ & $5 \%$ & $1,9 \%$ \\
\hline
\end{tabular}

However, Table 9 indicates some inconsistencies with these student statements. When students were asked to characterize the effect of the quality of their internet connection to the distance teaching and learning of Science, 1/3 answered "moderate" and another 1/3 answered "positive", corresponding with their previous answers. However, only 1/10 answered "very positive", a percentage that would be expected to have doubled in consistence with question 8 . In addition, the "negative" effects were three times more than would be reasonably expected (15,6\% vs. $5 \%)$.

It seems, therefore, that despite the high technical standards (powerful PCs processors, fiber optic networks, high speed data transmission, etc.) there were problems locally or occasionally with the connection platform (video clipping, audio blocking, repeated input requests, etc.), which led some students with a "very good" internet connection to finally form a "negative" impression of the distance teaching and learning of the subject. Similar problems related to technology and internet access were also found in other research concerning online education in tertiary education (Azlan et al., 2020; Bisht et al., 2020; Sharin, 2021). The parameter of internet access and use of technology was recorded as a great challenge during the COVID-19 pandemic period by global organizations (Reimers \& Schleicher, 2020; UNESCO, 2021), while it was also pointed out by teachers (An et al., 2021). Especially in Greece, "the majority of teachers (60\%) referred to technical issues which involve the lack of access to internet, lack of equipment, instability of internet connection and technical problems" (Gkaintartzi, 2021, p. 8).

Table 9. Effect of internet connection on distance teaching and learning of Science

\begin{tabular}{|c|c|c|c|c|}
\hline very positive & positive & moderate & negative & very negative \\
\hline $11,9 \%$ & $33,3 \%$ & $36,8 \%$ & $15,6 \%$ & $2,4 \%$ \\
\hline
\end{tabular}

The fact that the students were negatively affected by the quality of the available equipment and the quality of the internet connection is highlighted by the answers they gave to the hypothetical question "What would distance teaching and learning of Science be like if I had better equipment and the best quality with my internet connection?" About 2/5 of the students answered, "much better", another 2/5 answered "a little better", about 1/5 answered "same", while almost no student believed that the lesson would be worse (Table 10). 
Table 10. The distance teaching and learning of Science with better equipment and the best quality of internet connection

\begin{tabular}{|c|c|c|c|c|}
\hline much better & a little better & same & a little worse & much worse \\
\hline $37,3 \%$ & $39,2 \%$ & $22,8 \%$ & $0,8 \%$ & $0 \%$ \\
\hline
\end{tabular}

\subsection{Regarding students'communication with teacher and classmates}

Seven questionnaire questions were intended to record the quality of communication developed during the distance teaching and learning of Science. As shown in Table 11, the largest percentage of students $(48,7 \%)$ considered that communication with the teacher worsened during the distance teaching and learning of Science, a significant percentage $(43,4 \%)$ that remained the same and only $7,9 \%$ that improved in comparison with communication in face-to-face teaching.

Table 11. Students' communication with the teacher during the distance teaching and learning of Science

\begin{tabular}{|c|c|c|}
\hline worsened & remained the same & improved \\
\hline $48,7 \%$ & $43,4 \%$ & $7,9 \%$ \\
\hline
\end{tabular}

As seen in Table 12, communication with classmates worsened in comparison with the communication in face-to-face teaching, as stated by $67,2 \%$ of the students. The answers to these two questions are compatible with each other, as they agree that communication during the distance teaching and learning of Science is degraded, as it becomes less in quantity and more difficult in quality. However, it is noticeable that the degradation, the difficulty and the lack of communication with the classmates was pointed out to a greater extent than that with the teacher $(67,2 \%$ vs. $48,7 \%)$ by primary students. Similar findings for limited communication with the teacher and classmates in online education during COVID-19 pandemic were also identified by other researchers (Bisht et al., 2020; Radha et al., 2020).

Table 12. Students' communication with classmates during the distance teaching and learning of Science

\begin{tabular}{|c|c|c|}
\hline worsened & remained the same & improved \\
\hline $67,2 \%$ & $26,2 \%$ & $6,6 \%$ \\
\hline
\end{tabular}

Table 13 shows the students' answers to the question "How much did your teacher's way of teaching during distance teaching and learning of Science differ from the way he/she taught in the classroom?" The answers "much", "moderately", "a little" received each of $1 / 4$ of the answers, while the extreme answers "too much" and "not at all" received the rest $1 / 4$ of the answers equally divided. 
We consider that this distribution reflects the realistic picture of the conduct of the distance teaching and learning of Science (and perhaps not only of Science). The: school reality that was formed in Greece during the COVID-19 pandemic was based on the one hand on the desire of the teachers to respond to the new teaching conditions and on the other hand on the technological knowledge and skills that every teacher had. We consider that the variety of students' answers to this question records the different degree of teachers' response to the technological requirements of the distance teaching and learning, especially in a subject that request the use of supervisory tools, images, presentations, simulations and videotaped experiments.

Table 13. The differentiation of teacher's way of teaching during the distance teaching and learning of Science

\begin{tabular}{|c|c|c|c|c|}
\hline too much & much & moderately & a little & not at all \\
\hline $11,4 \%$ & $25,9 \%$ & $25,4 \%$ & $25,9 \%$ & $11,4 \%$ \\
\hline
\end{tabular}

In the following question, students were asked to define the effect of their teacher's way of teaching during the distance teaching and learning of Science on their understanding of concepts and procedures of Science. Table 14 does not show the same balanced distribution as Table 13, but a clear shift to the spectrum of positive effects. More than half of the students $(39,9 \%+13 \%)$ stated that teacher's way of teaching contributed positively to the understanding of concepts and procedures of Science that were taught by distance, while less than $10 \%$ evaluated this contribution negatively. In other words, according to the students, even small changes in teacher's way of teaching during the distance teaching and learning of Science seem to have positive effects on the learning outcomes.

Table 14. The effect of teacher's way of teaching on students' understanding during the distance teaching and learning of Science

\begin{tabular}{|c|c|c|c|c|}
\hline very positive & positive & moderate & negative & very negative \\
\hline $13 \%$ & $39,9 \%$ & $37,6 \%$ & $8,5 \%$ & $1,1 \%$ \\
\hline
\end{tabular}

Another part of the communicative dimension of the teaching is the tasks assigned by the teacher to the students as homework. When students were asked to define the number of tasks assigned by the teacher during the distance teaching and learning of Science, almost half $(46 \%)$ answered that it remained the same in comparison with those assigned to the real class. However, there was also a significant almost $40 \%(30,2 \%+9 \%)$ of students, who stated that the number of assignments decreased to some extent, while less than $15 \%(12,7 \%+2,1 \%)$ of students stated that the assignments increased to some extent during the distance teaching and learning of Science (Table 15). 
Table 15. Number of the tasks assigned by the teacher to the students during the distance teaching and learning of Science

\begin{tabular}{|c|c|c|c|c|}
\hline decreased a lot & decreased slightly & remained the same & increased slightly & increased a lot \\
\hline $9 \%$ & $30,2 \%$ & $46 \%$ & $12,7 \%$ & $2,1 \%$ \\
\hline
\end{tabular}

Table 16. Time devoted to the correction of the tasks assigned during the distance teaching and learning of Science

\begin{tabular}{|c|c|c|c|c|}
\hline decreased a lot & decreased slightly & remained the same & increased slightly & increased a lot \\
\hline $6,6 \%$ & $23,3 \%$ & $38,1 \%$ & $22 \%$ & $10,1 \%$ \\
\hline
\end{tabular}

However, the time devoted to the correction of the tasks assigned by the teacher during the distance teaching and learning of Science did not decrease correspondingly. On the contrary, it seems that the time for task corrections has increased in double cases compared with the cases that the number of tasks assigned has increased $(10,1 \%+22 \%=32,1 \%$ vs. $2,1 \%+12,7 \%=14,8 \%$ ) (Table 16). This apparent inconsistency can be explained by the insecurity felt by teachers about what their students actually understand by distance. In other words, the teachers further analyzed the answers to the tasks assigned so that as many students as possible understood the concepts, even if the tasks assigned were fewer in number compared to the real class.

Concerning the correction of the tasks assigned by the teacher during the distance teaching and learning of Science, this was done in a wide variety of ways, as shown in Table 17. In $35,2 \%$ of the cases the correction of the tasks assigned was done during the online learning in various ways with the contribution of teacher and students. We believe that this variety indicates the different degree of teachers' familiarity with the technological means in distance education, but also their effort to meet the different needs of their students.

Table 17. Ways of correction the tasks assigned by the teacher during the distance teaching and learning of Science

\begin{tabular}{|c|c|c|c|c|}
\hline $\begin{array}{c}\text { It was done by } \\
\text { the teacher and } \\
\text { sent to us online }\end{array}$ & $\begin{array}{c}\text { The teacher } \\
\text { sent us the } \\
\text { answers and } \\
\text { we made } \\
\text { self-correction }\end{array}$ & $\begin{array}{c}\text { It was set to be } \\
\text { done with the } \\
\text { opening of the } \\
\text { school and the } \\
\text { return to real class }\end{array}$ & $\begin{array}{c}\text { No } \\
\text { correction }\end{array}$ & $\begin{array}{c}\text { Other } \\
\text { (what?) }\end{array}$ \\
\hline $26,5 \%$ & $19 \%$ & $17,2 \%$ & $2,1 \%$ & $35,2 \%$ \\
\hline
\end{tabular}

\subsection{Regarding students'personal approach and involvement}

Six questionnaire questions were intended to record each student's personal involvement 
including final assessment questions. As shown in Table 18, when students were asked to define their concentration during the distance teaching and learning of Science, about half of them $(48,1 \%)$ thought it was the same as in the real class. However, the percentages of students who described it as lower were four times higher than those who described it as higher $(35,7 \%+6,3 \%=42 \%$ vs. $2,6 \%+7,1 \%=9,8 \%)$. Therefore, it seems that the home environment had many distractions and did not allow them in some extent to be concentrated in the distance teaching and learning of Science, a situation that probably applied to all subjects and not only to Science. The same finding of limited concentration is described in other researches for students of all ages (Azlan et al., 2020; Besser et al., 2020; Pensiero et al., 2020), even in Greece for secondary students (Kyriakou et al., 2021).

Table 18. Student's concentration during the distance teaching and learning of Science

\begin{tabular}{|c|c|c|c|c|}
\hline much higher & higher & $\begin{array}{c}\text { the same } \\
\text { as in the } \\
\text { real class }\end{array}$ & lower & much lower \\
\hline $2,6 \%$ & $7,1 \%$ & $48,1 \%$ & $35,7 \%$ & $6,3 \%$ \\
\hline
\end{tabular}

Similar answers were given by the students to the question asking for their personal participation in the distance teaching and learning of Science. The majority $(57,1 \%)$ of the students answered that they participated in the same extent as in the real class. However, the percentages of students who characterized their participation as lower were almost triple than those who characterized it as higher $(26,7 \%+4 \%=30,7 \%$ vs. $2,1 \%+10,1 \%=12,2 \%)$. This trend is compatible with previous findings, such as that the distance teaching and learning of Science was done in a more teacher-centered way and that the students' concentration was lower than in the real class. This finding is also consistent with those of other research, in which the active involvement of students of all ages decreased during distance education (An et al., 2021; Besser et al., 2020; Chen et al., 2010; Thurmond \& Wambach 2004).

Table 19. Student's personal participation during the distance teaching and learning of Science

\begin{tabular}{|c|c|c|c|c|}
\hline much higher & higher & $\begin{array}{c}\text { the same } \\
\text { as in the } \\
\text { real class }\end{array}$ & lower & much lower \\
\hline $2,1 \%$ & $10,1 \%$ & $57,1 \%$ & $26,7 \%$ & $4 \%$ \\
\hline
\end{tabular}

Table 20 records the evaluation of the learning outcomes of the distance teaching and learning of Science by the students, who were asked to think, decide and fill the sentence "I think that the concepts of Science that I better understood during distance teaching and learning of Science were..." The results are like the previous two questions. Roughly half of the students $(48,1 \%)$ thought that they understood the same number of concepts as in the real 


\section{Mll Macrothink}

class. However, the percentage of students who considered they understood fewer concepts were five times higher than those who considered they understood more concepts $(38,1 \%+5,3 \%=43,4 \%$ vs. $2,1 \%+6,3 \%=8,4 \%)$. Despite the young age of the students, they seem to feel that they lack a deep understanding of Science concepts and attribute this lack to the forced distance teaching and learning of Science applied during the COVID-19 pandemic. The same findings were recorded in another research in Greece for secondary students (Kyriakou et al., 2021).

Table 20. Understanding of concepts during distance teaching and learning of Science

\begin{tabular}{|c|c|c|c|c|}
\hline $\begin{array}{c}\text { much more } \\
\text { than in the real } \\
\text { class }\end{array}$ & $\begin{array}{c}\text { more than in } \\
\text { the real class }\end{array}$ & $\begin{array}{c}\text { the same } \\
\text { as in the } \\
\text { real class }\end{array}$ & $\begin{array}{c}\text { fewer than } \\
\text { in the real } \\
\text { class }\end{array}$ & $\begin{array}{c}\text { much fewer than } \\
\text { in the real class }\end{array}$ \\
\hline $2,1 \%$ & $6,3 \%$ & $48,1 \%$ & $38,1 \%$ & $5,3 \%$ \\
\hline
\end{tabular}

At the end of the questionnaire students were asked to answer in two open-ended questions in order to express their general opinion about the distance teaching and learning of Science during the COVID-19 pandemic stating what they liked and what they did not like concerning this teaching type. Tables $21-22$ present the given answers. 
Table 21. What did you like in the distance teaching and learning of Science?

\begin{tabular}{|l|c|c|}
\hline Content of answers & $\begin{array}{c}\text { Number of } \\
\text { answers }\end{array}$ & $\begin{array}{c}\text { Students' } \\
\text { percentage }\end{array}$ \\
\hline $\begin{array}{l}\text { Use of audiovisual material (video, ppt, simulations, etc) as } \\
\text { well as equipment (interactive pens, whiteboard, etc) }\end{array}$ & 123 & $32,5 \%$ \\
\hline No answer & 59 & $15,6 \%$ \\
\hline I like nothing at all & 50 & $13,2 \%$ \\
\hline Comfort of the house & 32 & $8,5 \%$ \\
\hline Higher concentration & 25 & $6,6 \%$ \\
\hline $\begin{array}{l}\text { The attitude of the teacher (not strict with students, leniency, } \\
\text { supporting, encouraging, great effort, etc) }\end{array}$ & 24 & $6,3 \%$ \\
\hline I can't distinguish anything special & 20 & $5,3 \%$ \\
\hline Short teaching time & 18 & $4,8 \%$ \\
\hline $\begin{array}{l}\text { Various answers (engaging in other things during the lesson, } \\
\text { communicating via chat, etc) }\end{array}$ & 18 & $4,8 \%$ \\
\hline Without masks & $3 \%$ \\
\hline Dividing and working in groups (breakout sessions) & & $0,8 \%$ \\
\hline Tabe 21 shows that the great eductional benefit & & \\
\hline
\end{tabular}

Table 21 shows that the greatest educational benefit of distance teaching and learning of Science was the use of rich supervisory sources, which were used even more in Science in comparison with other subjects, as also stated in a previous closed-ended question (Table 5). In addition, it seems that the teachers developed their skills in using online platform management systems, a fact indicated using interactive pens or other technological tools throughout online learning. Answers indicating facilities of the students, such as the comfort of the house, the short duration of the teaching hour and the non-requirement of wearing a mask were declared by the students in percentages less than $8,5 \%$. It is noticeable that $6,6 \%$ of the students stated as an advantage of the distance teaching and learning of Science the higher concentration they experienced at home compared to the real class, a percentage that is in accordance with students' views in the corresponding closed-ended question (Table 18). Finally, we consider as remarkable that $6,3 \%$ of the students felt the need to state as an advantage of the distance teaching and learning of Science the attitude of the teacher, who 
showed increased leniency to the students, while he/she made an obvious effort to meet the difficult requirements of the distance teaching and learning, given that about $33 \%$ of the primary teachers in Greece did not have any kind of prior knowledge on distance and online teaching (Gkaintartzi, 2021, p.6)

Table 22. What did you dislike in the distance teaching and learning of Science?

\begin{tabular}{|l|c|c|}
\hline Content of answers & $\begin{array}{c}\text { Number of } \\
\text { answers }\end{array}$ & $\begin{array}{c}\text { Students } \\
\text { percentage }\end{array}$ \\
\hline $\begin{array}{l}\text { Technical problems (poor or incomplete connection, frequent } \\
\text { interruptions, sound problems, etc.) }\end{array}$ & 128 & $33,8 \%$ \\
\hline $\begin{array}{l}\text { Lack of communication and interaction with classmates and } \\
\text { teacher }\end{array}$ & 105 & $27,7 \%$ \\
\hline $\begin{array}{l}\text { Lack of implementation of live experiments } \\
\text { Isolation, inability to concentrate, sitting in front of a computer } \\
\text { all day (eye strain, headaches, etc) }\end{array}$ & 25 & $11,9 \%$ \\
\hline $\begin{array}{l}\text { Ineffective teaching (only for curriculum coverage, insufficient } \\
\text { time for further explanations and questioning, etc) }\end{array}$ & 24 & $6,6 \%$ \\
\hline $\begin{array}{l}\text { There is nothing to dislike } \\
\text { short breaks, generally the way of teaching, lack of time, etc.) }\end{array}$ & 21 & $5,3 \%$ \\
\hline I dislike everything & 17 & $4,4 \%$ \\
\hline \begin{tabular}{l} 
No answer \\
\hline
\end{tabular} & $4,5 \%$ \\
\hline
\end{tabular}

Table 22 shows that the distance teaching and learning of Science faced two major problems: technical connection problems and lack of communication with classmates and teacher. These answers confirm the answers to the closed-ended questions. For example, 36,2\% of students had characterized the quality of their internet connection as moderate, $5 \%$ as poor and $1,9 \%$ as very poor (Table 8 ) and a similar view is formed by a total of $33,8 \%$ of students in this open-ended final question. In addition, $48,7 \%$ of students had stated that communication with the teacher worsened (Table 11) and 67,2\% that communication with classmates also worsened (Table 12) and 27,7\% stated that this lack has remained as a final impression. Our research confirms the findings of other researchers even at other levels of education both in terms of identifying technical connection problems (Azlan et al., 2020; Bisht et al., 2020; Kyriakou et al., 2021; Reimers \& Schleicher, 2020; Sharin, 2021) and also in terms of lack of 


\section{NI Macrothink}

communication (An et al., 2021; Besser et al., 2020; Bisht et al., 2020; Radha et al., 2020).

Limited involvement, passive participation, and difficulty to concentrate were reported as "dislike elements" by $6,6 \%$ of students in accordance with other researches for students of all ages (An et al., 2021, Besser et al., 2020, Chen et al., 2010, Di Pietro et al., 2020; Gray \& Diloreto 2016; Pensiero et al., 2020, Sharin, 2021). Moreover, ineffective teaching was declared as the final educational result by $6,3 \%$ of students in accordance with statements in the corresponding closed-ended question, where students stated that they had understood fewer concepts of Science through distance teaching and learning of Science compared to real class teaching (Table 20).

The combination of all the above findings, ie the coexistence of technical problems, lack of communication, limited participation and learning deficiencies contributes to the creation of psychological effects such as stress and anxiety in students, as recorded by other researchers (Azlan et al., 2020, Besser et al., 2020, Di Pietro et al., 2020; Sharin, 2021). In our case, these psychological effects may not have been verbally declared by the students, but they emerge through what students "did not like" or missed during the distance teaching and learning of Science (Table 22). We consider that similar feelings were expressed through characteristic words or phrases, such as "we were isolated", "we did not have time to ask", "we were sitting for hours" and "we only had short breaks".

Finally, it is noticeable that $11,9 \%$ of students pointed out as a negative element of the distance teaching and learning of Science the lack of live experiments, a significant requirement in the teaching of Science. Note that in Table 22 the answers are a little more than the total number of students, as some students gave more than one answer.

Through the last question of the questionnaire, after the experience of the distance teaching and learning of Science, the students were asked to evaluate "Finally, in your opinion, in which case is the subject of Science taught better?" The vast majority $(85,4 \%)$ clearly declared a preference in real class teaching. We consider this final opinion to be consistent with two of the previous findings. First, with the data of Table 2 where more than $9 / 10$ of the students had positive evaluations for the way of teaching Science in the real class and of Table 3 where only $3 / 10$ of the students had positive evaluations for the distance teaching and learning of the subject. Second, with individual elements that did not seem to satisfy the students, such as communication with the teacher (Table 11), communication with classmates (Table 12), lower concentration (Table 18), less personal involvement (Table 19) and limited understanding of concepts (Table 20). Based on these individual statements, it was expected that students would not finally prefer distance teaching and learning perhaps for all school subjects. However, the huge difference in preferences of Table 23 shows that in Science live teaching is irreplaceable and this is perceived even by primary education students. In a similar question, the same preference for live learning in rate of $77,71 \%$ was shown by higher education students, even if not focused on Science (Radha et al., 2020). Similarly, head teachers in Greece found that "distance learning was a painful endeavor which has led to a burnout of both teachers and students" (Geropoulos et al., 2021, p. 64) and 25\% of teachers in Greece found "absolutely no benefits and advantages to be gained from online 
teaching/learning" (Gkaintartzi, 2021, p. 10).

Table 23. Final preference of students for the teaching of Science

\begin{tabular}{|c|c|c|}
\hline by distance & $\begin{array}{c}\text { the same in both } \\
\text { ways }\end{array}$ & in real class \\
\hline $3,7 \%$ & $10,8 \%$ & $85,4 \%$ \\
\hline
\end{tabular}

\section{Conclusions and Implications}

Education was significantly affected by the COVID-19 pandemic worldwide. In Greece, distance education was implemented as a solution to maintain contact with students at all levels in an asynchronous and then in synchronous form (online learning). Based on the findings of the present research it becomes clear that the students were not satisfied with the distance teaching and learning of Science and state that they prefer to be taught this subject in the real class. The main reasons mentioned by the students that lead them to this overview are the appearance of problems in the connection platform and the quality of the internet connection, the lack of experiments with their active participation, the restriction of discussions, the reduction of group work, the difficulty of communicating with the teacher and classmates, the impaired concentration at home and their limited personal involvement. As a result, the students themselves conclude that during the distance teaching and learning of Science they had a lower understanding of concepts and procedures of Science.

Students' answers can be used as a guide for designing a successful distance teaching and learning of Science. Positive results in activating students' interest and active participation are offered by the general effort of the teacher and the utilization of many supervisory materials and applications (simulations, ppt, videotaped experiments, etc.). Elements that should be avoided are technical problems, teacher-centered process, reduced communication, lack of discussion, prevention of questions, "hunting for the curriculum". Similar suggestions are made by other researchers, who suggest as qualitative characteristics of the successful online courses clearly written objectives, well-organized content, variety of opportunities for interpersonal interaction, and effective use of technology (Jaggars \& Xu, 2016).

Data for this research were collected from a limited number of primary schools. The inherent bias in convenience sampling, due to under-representation of particular subgroups in the sample, does not allow trustworthy inferences to be made about the intended population. In addition, due to the voluntary nature of the research, it is possible that the views of students having a more positive view of Science, greater interest in the subject, better internet access and greater participation in the online learning were recorded. For the most accurate way of perceiving the distance teaching and learning of Science by students of primary education, a larger scale research is required with participation of all the students in each class and with an even more specialized research tool. Of course, restrictions on social distances and rules to avoid overcrowding do not allow such projects as long as the COVID-19 pandemic lasts. Even more accurate conclusions for distance teaching and learning of Science would be given 


\section{NI Macrothink}

Journal of Studies in Education

ISSN 2162-6952

2022, Vol. 12, No. 1

by a corresponding research addressed to primary education teachers, a step that our research team already prepares.

In any case, we consider the present research as a useful guide for designing the distance teaching and learning of Science for primary students. Topics that were discussed in the educational community were confirmed with real data, which are of special value, because they come from the students themselves. It is now up to those who have the responsibility of educational policy, plan the curriculum or organize teacher training to take into account the requirements of the distance teaching and learning (not only of Science), in order to cover as successfully as possible the dimensions and specific features of the distance education of each subject.

\section{References}

An, Y., Kaplan-Rakowski, R., Yang, J., Conan, J., Kinard, W., Daughrity, L. (2021). Examining K-12 teachers' feelings, experiences, and perspectives regarding online teaching during the early stage of the COVID-19 pandemic. Educational Technology Research Development, 28, 1-25. https://doi.org/10.1007/s11423-021-10008-5

Angelova, S. (2021). Development of Student Teacher's Satisfaction with e-Learning Science Course. AIP Conference Proceedings 2333, 050011. https://doi.org/10.1063/5.0042071

Azlan, C. A., Wong, J. H. D., Tan, L. K., Nizam, M. S., Huri, Ung, N. M., Pallath, V., Tan, C. P. L., Yeong, C. H., Ng K. H., (2020). Teaching and learning of postgraduate medical physics using Internet-based e-learning during the Covid-19 pandemic: A case study from Malaysia. Physica Medica, 80, 10-16. https://doi.org/10.1016/j.ejmp.2020.10.002

Besser, A., Flett, G. L., \& Zeigler-Hill, V. (2020). Adaptability to a sudden transition to online learning during the Covid-19 pandemic: Understanding the challenges for students. Scholarship of Teaching and Learning in Psychology. https://doi.org/10.1037/st10000198

Bisht, R. K., Jasola, S., \& Bisht, I. P. (2020). Acceptability and challenges of online higher education in the era of Covid-19: a study of students' perspective. Asian Education and Development Studies. https://doi.org/10.1108/AEDS-05-2020-0119

Center for Studies and Documentation of Federation of Secondary Education Officials (KEMETE) (2021). Aspects of e-learning during the pandemic: Educational inequalities and implications for labor rights (in Greek).

Chen, P. S. D., Lambert, A. D. \& Guidry, K. R. (2010). Engaging online learners: the impact of web-based learning technology on college student engagement. Computers \& Education, 54(4), 1222-1232. https://doi.org/10.1016/j.compedu.2009.11.008

Di Pietro, G., Biagi, F., Dinis Mota Da Costa, P., Karpinski, Z. and Mazza, J. (2020). The likely impact of COVID-19 on education: Reflections based on the existing literature and recent international datasets, EUR 30275 EN, Publications Office of the European Union, Luxembourg, ISBN 978-92-76-19937-3 (online), JRC121071

Ferraro, V. F., Ambra, I.F., Aruta, L. \& Iavarone, L.M. (2020). Distance Learning in the 
COVID-19 Era: Perceptions in Southern Italy. Education Sciences, 10(12), 355. https://doi.org/10.3390/educsci10120355

Geropoulos, P, Tsioumis, K. \& Loufopoulos, I. (2021). Pedagogical Leadership Practices for the Management of Covid-19 Pandemic in the Greek School System. Journal of Studies in Education, 11(3), 59-72. https://doi.org/10.5296/jse.v11i3.18726

Gewin, V. (2020). Five tips for moving teaching online as COVID-19 takes hold. Nature, 580, 295-296. https://doi.org/10.1038/d41586-020-00896-7

Gkaintartzi, A. (2021. Teachers' perspectives about distance education for refugee students amid the COVID-19 pandemic in Greece: Challenges and Implications, Journal of Studies in Education, 11(4), 1-16. https://doi.org/10.5296/jse.v11i4.19003

Gray, J. A. \& Diloreto, M. (2016). The effects of student engagement, student satisfaction, and perceived learning in online learning. International Journal of Educational Leadership Preparation, 11(1), 98-119

Jæger, M. M., \& Blaabæk, E. H. (2020). Inequality in Learning Opportunities during Covid-19: Evidence from Library Takeout. Research in Social Stratification and Mobility, 68, 1-5. https://doi.org/10.1016/j.rssm.2020.100524

Jaggars, S. S., \& Xu, Di (2016). How do online course design features influence student performance? Computers and Education, 95, 270-284. https://doi.org/10.1016/j.compedu.2016.01.014

Karadimou, M. \& Tsioumis, K. (2021). Covid-19 Pandemic; Is this an Opportunity for an Educational Big-Bang? Journal of Studies in Education, 11(4), 42-56. https://doi.org/10.5296/jse.v11i4.19015

Kyriakou, K., Stefanidou, C., Mandrikas, A., Stavrou, I. \& Skordoulis, C. (2021). Distance learning of Science during the COVID-19 pandemic: recording the degree of satisfaction of high school students. Educational Review, 38(71), 31-49, Hellenic Educational Society, Diadrasi, Athens, Greece (ISSN 1106-2177) (in Greek)

Martin, E. \& Bolliger, D. U. (2018). Engagement matters: students' perceptions on the importance of engagement strategies in the online environment. Online Learning, 22(1), 205-222. https://doi.org/10.24059/olj.v22i1.1092

Mayring, P. (2015). Qualitative Content Analysis: Theoretical Background and Procedures. In A. Bikner-Ahsbahs, C. Knipping, \& N. Presmeg (Eds.), Approaches to Qualitative Research in Mathematics Education (pp. 365-380). Dordrecht: Springer. https://doi.org/10.1007/978-94-017-9181-6_13

Meyer, K. (2019). Students' perceptions of face - to - face and online discussions: The advantage goes to... Online Journal of Distance Learning, 11(4). https://doi.org/10.24059/olj.v11i4.1715

Moroni, G., Cheti, N., and Tominey, E. (2020). Children's socio-emotional skills and the 
home environment during the COVID-19 crisis. VOX Cepr Policy Portal

Muzammil, M., Sutawijaya, A. \& Harsasi, M. (2020). Investigating Student Satisfaction in Online Learning: The role of student interaction and engagement in Distance Learning. Turkish Online Journal of Distance Education, 21(special): 88-96. https://doi.org/10.17718/tojde.770928

Pensiero, N., Kelly, A. \& Bokhove, C. (2020). Learning inequalities during the Covid-19 pandemic: how families cope with home-schooling. University of Southampton 20pp

Radha, R., Mahalakshmi, K., Kumar, S. \& Saravanakumar, A. (2020). E-Learning during Lockdown of Covid-19 Pandemic: A Global Perspective. International Journal of Control and Automation, 13(4), 1088-1099

Reimers, F. M., \& Schleicher, A. (2020). A framework to guide an education response to the COVID-19 Pandemic of 2020. OECD.

Sharin, A. N. (2021). E-Learning During Covid-19: A Review of Literature. Malaysian Journal of Media Studies, 23(1), 15-28. https://doi.org/10.22452/jpmm.vo123no1.2

Thurmond, V., \& Wambach, K. (2004). Understanding interactions in distance education: A review of the literature. International Journal of Instructional Technology \& Distance Learning, 1, 9-33.

UNESCO (2020). COVID-19 and higher education: Today and tomorrow. Impact analysis, policy responses and recommendations. UNESCO-IESALC

UNESCO (2021). Supporting learning recovery one year into COVID-19. The Global Educator Coalition in action. UNESCO, March 2021

Watts, L. (2016). Synchronous and asynchronous communication in Distance Learning: a review of the literature. Quarterly Distance Education, 17(1), 23-32

\section{Copyrights}

Copyright for this article is retained by the author(s), with first publication rights granted to the journal.

This is an open-access article distributed under the terms and conditions of the Creative Commons Attribution license (http://creativecommons.org/licenses/by/4.0/) 